\title{
Chemical disinfection in the prevention of infection in hospital
}

\author{
W. A. GILLESPIE \\ From the Royal Infirmary, Bristol
}

SYNOPSIS Much cross-infection can be prevented by using chemical disinfectants to reduce the numbers of pathogens in sources such as superficial lesions and carrier sites, and by interrupting routes of spread. Examples are given to show the value of using disinfectants in the light of epidemiological knowledge.

When aseptic surgery superseded the antiseptic methods of Lister, its advantages were so obvious that its shortcomings were sometimes overlooked. It was often assumed, quite wrongly, that complete sterility could be achieved at the operation site by physical and mechanical methods of excluding and destroying bacteria. Disinfectants and antiseptics (that is, disinfectants which can be safely applied to tissues) continued in use. But on the whole they were used empirically and with insufficient understanding of their limitations. This was perhaps the inevitable result of difficulties inherent in the realistic evaluation of disinfectants. Laboratory tests of their activity in vitro often gave little guidance as to their clinical value. The resulting uncertainties in choosing between the different agents available and in deciding what concentrations to employ have caused much confusion.

Recent years have brought a lively realization of the limitations of the aseptic methods as practised in operating theatres. Some defects have resulted from faulty methods of heat sterilization. But correction of such faults, although important, cannot provide sterile operating fields. Even if instruments, dressings, and fabrics are sterile, bacteria may reach susceptible tissues in several ways, for example, from the air, from the patient's skin or mucous membrane at the site of operation, and from the surgeon's skin through holes in his gloves or through the sleeve of his gown if it becomes wet. Sources and vectors of infection such as these cannot be completely sterilized; but the amount of contamination (except for the air) may be greatly reduced by means of disinfectants.

In the wards and labour rooms, as in the theatre, prevention of infection should be based primarily on physical and hygienic measures, such as the provision of heat-sterilized instruments and dressings, the use of non-touch techniques, and the avoidance of overcrowding. Disinfectants and antiseptics are not substitutes for good hygiene but should supplement it. Experience has shown, however, that the supplementation may be very valuable, and may substantially reduce cross-infection rates which, even in well-conducted wards, are sometimes disturbingly high.

In the control of hospital infection, therefore, chemical disinfection plays an important, though incomplete, role. Here it is appropriate to recall the distinguished pioneer work of Leonard Colebrook on the epidemiology and prevention of streptococcal puerperal infection and of infection in burns (Colebrook, 1950; 1954). Colebrook's work provided valuable patterns for subsequent investigations in other fields by demonstrating the importance of a $\frac{?}{0}$ thorough understanding of the epidemiological $\frac{0}{7}$ behaviour of the pathogens, and the value of combining physical methods, antiseptics, and systemic $\delta$ chemotherapy for the control of infection.

This paper describes some applications of chem- 을 ical disinfection to the prevention of infection in $>$ general and maternity hospitals. It does not contain a comprehensive account of disinfectants and $\bar{N}$ their uses. For this, reference should be made to textbooks such as those by Sykes (1958) and $N$ Williams, Blowers, Garrod, and Shooter (1960).

In theory, cross-infection might be prevented by interrupting the routes of spread of the pathogens, $\infty$ or by eliminating their sources. In practice, a com- $\frac{C}{\Phi}$ bined attack usually succeeds best. The ability of a $\stackrel{\mathscr{P}}{+}$ pathogen to cause infection depends on its numbers $\square$ as well as on its virulence. Hence, even when several $\stackrel{\circ}{\vec{P}}$ vectors of infection can be recognized and treated, $\stackrel{\Phi}{\overparen{D}}$ it is wise to pay attention also to the sources, in order $\mathbb{\mathbb { D }}$ to reduce the load of infection as much as possible. $\frac{}{\sigma}$ It may be practicable to remove the sources by 
isolating all patients with open infections. But in obstetric and surgical units, full isolation may be impracticable; and in any case, many sources cannot be recognized without elaborate bacteriological study. In these circumstances, much can be achieved by the chemoprophylactic treatment of potential sources (superficial open lesions and carrier sites) in order to protect them from colonization by the pathogen, or at any rate restrict its multiplication. It is usually easier to exclude the pathogen from a potential source than to eliminate it from a site already infected by it. The effectiveness of chemoprophylaxis varies greatly in different circumstances. Its greatest successes have been achieved in burns units and against staphylococci in maternity hospital nurseries, where the potential sources are very superficial and accessible to topical antiseptics.

Programmes for the prevention of cross-infection preferably should be selective, with emphasis on measures against demonstrably important sources and vectors. Thus, for the control of staphylococcal infection in surgical wards, it is more important to disinfect the baths, the bedding, and the nurses' hands than the walls and floor; and in maternity units, environmental hygiene will be largely wasted unless the staphylococci are prevented from multiplying freely in the infants' carrier sites. Nevertheless, a bactericidal system which would destroy pathogens in all parts of the hospital environment, including the air, might have much to commend it. The system described by Hudson, Sanger, and Sproul (1959) uses this approach. Complex mixtures of chemicals (for particulars of which reference should be made to the original article) were used regularly to disinfect a wide variety of fomites, including floors, baths, bedding, etc. Air was treated by re-circulating it through disinfectant-treated filters. Substantial reductions in the numbers of airborne bacteria were observed. Preliminary experience at the Hammersmith Hospital has confirmed these findings, but further observations will be needed to determine the effect on cross-infection (Mary Barber, personal communication).

Chemicals with selective antibacterial activities, although poor general disinfectants, may be useful for controlling particular infections. Thus, hexachlorophene and quaternary ammonium compounds are valuable for prophylaxis of staphylococcal infection but not of infection by Pseudomonas pyocyanea. Antibiotics such as neomycin and bacitracin, which are rarely administered systemically, may be applied as topical antiseptics. They should be used in combinations, or mixed with synthetic agents such as chlorhexidine, in order to minimize the risk of producing resistant strains.

\section{DISINFECTANTS AND THE PREVENTION OF PARTICULAR INFECTIONS}

HAEMOLYTIC STREPTOCOCCAL INFECTIONS IN OBSTETRICS. Reference has already been made to the pioneer work of Leonard Colebrook. The declining incidence of peurperal sepsis, following the introduction of sulphonamides and penicillin, has not lessened the importance of asepsis and antisepsis in midwifery. The demonstration by Colebrook and Maxted (1933) that chloroxylenol was actively and persistently lethal to streptococci in concentrations which were harmless to tissues showed the way to chemoprophylactic procedures in other fields and against other organisms. Newer disinfectants, such as chlorhexidine, might be preferable to chloroxylenol for obstetrical use; but the infrequency of streptococcal infections nowadays makes it difficult to compare different disinfectants.

INFECTION OF BURNS Burns very readily become colonized or infected by a variety of organisms, of which the most important is Streptococcus pyogenes. Staphylococcus aureus, coliform bacilli, and Ps. pyocyanea are also common, but their pathogenic roles are less firmly established. Methods of reducing infection have been intensively studied in work initiated by Leonard Colebrook and his colleagues in Glasgow (Colebrook, Gibson, Todd, Clark, Brown, and Anderson, 1944) and later in Birmingham. Their aim was not to achieve sterility but to exclude the more important pathogens, particularly Str. pyogenes. Their methods were mainly physical (plenum ventilation and 'non-touch' techniques) but were supplemented by chemoprophylaxis with penicillin cream applied topically. Lowbury and his colleagues in Birmingham have continued to evaluate these and other techniques, in an important series of controlled trials (Lowbury, 1960). Topical applications of antibacterial agents were shown to have considerable value. The incidence of streptococcal infections was greatly diminished by prophylaxis with penicillin cream $(1,000$ unit/g.). Infection by $P s$. pyocyanea and coliform bacilli was diminished to a lesser, but still significant degree, by means of polymyxin cream $(1 \mathrm{mg} . / \mathrm{g}$.). Staphylococcal infections were often prevented by creams containing neomycin (2 mg./g.) and chlorhexidine $(1 \mathrm{mg} . / \mathrm{g}$.). A cream containing polymyxin, neomycin, and chlorhexidine was effective in prophylaxis against all the organisms; many burns remained apparently sterile, and added infection by Staph. aureus, in particular, was greatly reduced.

The work of Lowbury and his colleagues also threw light on the pathogenic roles of the bacteria which commonly colonize burns. The exclusion of 
Str. pyogenes greatly increased the percentage of successes with skin grafting (Lowbury and Cason, 1954). Similar improvements in healing were observed when burns were protected from Ps. pyocyanea and Staph. aureus, thus providing evidence that these species also are harmful to burns, and should not be dismissed as saprophytes (Jackson, Lowbury, and Topley, 1951; Lowbury, 1957).

STAPHYLOCOCCAL INFECTION IN MATERNITY HOSPITALS The part played by staphylococcal sources can be clearly observed in maternity hospital nurseries. The organisms are able to multiply rapidly, chiefly in the carrier sites of the infants themselves (Cunliffe, 1949; Gillespie, Simpson and Tozer, 1958; Hurst, 1960), and so produce an enormous staphylococcal 'pool' from which infection is readily spread to other infants and to adults. Keeping the infants in separate rooms with their mothers may lessen the danger though it does not remove it, so long as the infants are handled by a common nursing staff. Gillespie $e t$ al. (1958) found that the principal carrier sites were the umbilicus, nose, groin, and perineum, and less often, other flexures. Fortunately, all these sites are readily accessible to antiseptics. Farquharson, Penny, Edwards, and Barr (1952) and Baldwin, Rheins, Sylvester, and Shaffer (1957) reduced crossinfection by bathing the infants in solutions of hexachlorophene. In Bristol, as in many other centres, daily bathing of infants is not practised, and it was therefore found more convenient (and at least as effective) to apply hexachlorophene in a dusting powder. The infants are cleaned with sterile cotton wool and saline soon after birth. The cord remnant is trimmed short, and sealed with a plastic material (Octaflex), and a pre-sterilized talcum powder containing hexachlorophene $0.3 \%$ (Ster-Zac) is freely applied to the umbilical area, groins, perineum, axillae, and trunk, before the infant goes to the nursery. Thereafter the dusting is repeated every time the napkin is changed. In controlled trials, this treatment was found to reduce staphylococcal carriage by umbilicus and skin to small fractions of their previous levels, and to halve the incidence of nasal carriage. The incidence of skin sepsis among the infants was reduced from about $6 \%$ to less than $1 \%$ (Simpson, Tozer, and Gillespie, 1960), and there was a corresponding reduction in the incidence of maternal breast abscesses (Corner, Crowther, and Eades, 1960).

In recent trials (to be reported separately), the anterior nares of the powdered infants were treated once a day with a water-miscible cream (Naseptin) containing neomycin sulphate $(0.5 \%)$ and chlorhexidine hydrochloride $(0 \cdot 1 \%)$. There was a further slight reduction in the infants' sepsis rate, but since this was already low, the improvement was necessarily small. Further experience will be needed to determine the clinical value of prophylactic nasal cream used in addition to hexachlorophene powder. The two measures together greatly reduced the numbers of 'hospital' staphylococci carried by the infants and mothers into the outside population (Donnison, Gillespie, Simpson, and Tozer, 1960).

Hexachlorophene powder is now used routinely in all maternity nurseries in Bristol. Several thousands $\vec{\circ}$ of infants have been treated, with no skin irritation or other untoward effect. A powder containing chlorhexidine $1 \%$ was equally effective in preventing cross-infection, but caused some delay in the separation of the umbilical cord stump (unpublished observations).

The success obtained from treating sources was in striking contrast to the disappointing results of treating vectors. However, a controlled trial showed that the disinfection of nurses' hands with $1 \%$ chlorhexidine cream caused a small but significant reduction of cross-infection among the infants (Gillespie et al., 1958).

URINARY INFECTION IN UROLOGY AND GYNAECOLOGY Urinary infection often follows prostatectomy and continuous drainage of the bladder by indwelling catheter (Dukes, 1928; Durham, Shooter, and Curwen, 1954; Gillespie, 1956; Gillespie, Linton, Miller, and Slade, 1960). Kass (1957) found that even a single catheterization carried a $2-4 \%$ risk of infection. The causative organisms sometimes come from the patient himself, and sometimes from others, by a variety of routes. But except when an additional portal of entry has been artificially created, e.g., by suprapubic bladder drainage, there is only one important final route of infection, the urethra and the indwelling catheter lying in it.

To prevent infection, it is necessary to destroy any 8 pathogens which may have entered the urethra before instrumentation, and to exclude them during and 0 after operation. Alternatively, bacteria which have entered the bladder may be washed out again with antiseptics. These principles may be applied as follows:

Prostatectomy The urethra may be disinfected $N$ by instilling $5-10 \mathrm{ml}$. of $0.05 \%$ chlorhexidine in glycerine, as soon as the patient is anaesthetized and $O$ causing it to be retained for about 10 minutes. The same solution may be used to lubricate urethral instruments. Infection transferred on cystoscopes $\stackrel{\mathcal{D}}{\rightarrow}$ from other patients may be avoided by ensuring that the instruments are thoroughly disinfected, after rinsing with water, by vertical immersion in an $\mathbb{\odot}$ aqueous solution of chlorhexidine $1 / 5,000$ with mer- $\frac{}{\mathbb{D}}$ curic oxycyanide $1 / 2,000$ for 15 minutes, or in $0.2 \%$ 
chlorhexidine in $70 \%$ spirit for two minutes. Alternatively, the instruments may be disinfected by 'pasteurization' as described by Francis (1959). Retrograde infection via the indwelling catheter can usually be prevented by draining and irrigating the bladder by means of a closed apparatus in which sterility is maintained by formaldehyde (Miller, Gillespie, Linton, Slade, and Mitchell, 1958). The adoption of all these measures brought about a reduction of urinary infection after retropubic and transurethral prostatectomy from $83 \%$ to $6 \%$ (Gillespie et al., 1960).

Simple Bladder Drainage With open drainage, infection is almost inevitable. The lower end of the drainage tube becomes heavily contaminated by contact with urine in the collecting vessel, and bacteria are readily carried up by bubbles which ascend in the tube when the patient moves. It is therefore important to keep the collecting urine sterile, and desirable also to exclude air bubbles. In the method described by Miller, Linton, Gillespie, Slade, and Mitchell (1960), these purposes are achieved by keeping the end of the drainage tube below the surface of liq. formaldehyde B.P.C. The apparatus is simpler than that used for prostatectomy patients since there is no need to wash out blood clots. The collecting bottle must be kept below the level of the bladder so as to avoid the risk of siphoning formalin back. A narrow-bore plastic catheter should be used to minimize urethritis (Gibbon, 1958). The use of this method for draining the bladders of patients with acute retention of urine reduced the incidence of infection from $73 \%$ to $10 \%$ (Miller et al., 1960).

Kass and Sossen (1959) adopted a different approach to the problem of preventing infection with continuous drainage. They irrigated the bladder continuously with $0.25 \%$ acetic acid, in order to destroy, or wash out, any organisms which had entered it. The rate of irrigation was controlled by means of an electrical device. The infection rate was reduced from $100 \%$ to $10 \%$.

Gynaecological Operations The bladder usually has to be emptied artificially for some time after a colporrhaphy operation. This is sometimes carried out by inserting an indwelling catheter for the first few post-operative days, followed if necessary by intermittent catheterization for another day or so, until normal micturition is completely restored. Alternatively, the bladder may be intermittently catheterized from the start. In one hospital, where the former procedure was used with open drainage, $98 \%$ of the patients acquired urinary infections. The incidence was reduced to $76 \%$ by substituting closed for open drainage; most of the patients now became infected during the subsequent intermittent catheteri- zation (Gillespie et al., 1960). The main sources of infection were considered to be the contaminated open drainage apparatus, and the patient's own urethra.

Paterson, Barr, and Macdonald (1960) also reported a very high incidence of infection (92.5\%) in patients treated by indwelling catheter (presumably with open drainage). By changing to intermittent catheterization, the incidence of infection was reduced to $70 \%$. Paterson and his colleagues then tried the effect of instilling $2 \mathrm{oz}$. of 1 in 5,000 (w/v) aqueous solution of chlorhexidine diacetate into the bladder after every catheterization. This procedure brought about a notable improvement, with a fall in the infection rate to $13.5 \%$.

It may not always be desirable to instil disinfectant into the bladder. It might also be possible to protect the patient from infection by disinfecting the urethra before passing the catheter. This method is now being tested in Bristol. A solution of chlorhexidine digluconate $0.5 \%(\mathrm{w} / \mathrm{v})$ is made up in a mixture of polyethylene glycols and water, which is semi-solid at room temperature but quickly liquefies at body temperature (G. H. Darling, personal communication). A small quantity is introduced into the urethra about a minute before catheterization, by means of a special syringe. Preliminary results with this method have been encouraging.

Urine as a Reservoir of Infection An open drainage apparatus may be an important reservoir of cross-infection. Gram-negative bacilli and other organisms multiply in the collecting vessels and contaminate the hands of the nurses who empty them. The introduction of a closed drainage apparatus containing formaldehyde was followed by the disappearance of several antibiotic-resistant strains from the wards in which they had previously been endemic (Gillespie et al., 1960). Urine bottles and bedpans may also constitute reservoirs of infection in urological wards. McLeod (1958) pointed out that nurses' hands may be contaminated when rinsing and emptying urine bottles; urine should therefore be disinfected before emptying the bottles, which should then be terminally disinfected.

Urine containing staphylococci is especially dangerous in surgical wards. The procedure adopted to minimize this danger in a ward in the Bristol Royal Infirmary (with several urological beds) is to add $1 \mathrm{ml}$. of Tego 51 to each bottle before use. (For information about Tego compounds, which were developed in Germany, see Frisby, 1959.) This method is not entirely satisfactory, however, especially when the urine contains a large amount of pus. Other methods should be investigated in order to find a reliable, cheap, safe, and convenient procedure. 


\section{STAPHYLOCOCCAL INFECTION IN SURGICAL WARDS}

The chief sources of infection are the noses of patients who become carriers, and the open lesions (e.g., open and drained wounds, bedsores, etc.) which readily become colonized by staphylococci. Urine, sputum, and furuncles and infected closed wounds which discharge staphylococcal pus are also important, though usually less numerous than the firstmentioned sources. Many of the lesions are not superficial enough to be easily protected by local chemoprophylaxis. Hence, staphylococcal crossinfection is more difficult to control in surgical wards than in maternity units. Nevertheless, a combination of disinfectant measures directed against important potential sources and vectors can greatly reduce the amount of cross-infection. In prolonged controlled trials in Bristol, staphylococcal infections were reduced to about one-third of their former frequency in a ward where several precautions were simultaneously applied (Gillespie, Alder, Ayliffe, Bradbeer, and Wypkema, 1959). Subsequent experience in two more wards was similar, and showed that when the load of infection has been reduced, some precautions may be discontinued, at any rate temporarily, without the cross-infection rate returning to its former value (results to be published separately).

The system now used in the Bristol Royal Infirmary is to apply all the precautions together for several weeks, and later to withdraw one measure (the Polybactrin spray). The precautions are as follows:

AGAINST SOURCES 1. For nasal prophylaxis, neomycin-chlorhexidine cream (see above) is applied twice daily to the anterior nares of all patients from the day of admission. The cream is smeared inside each nostril with the finger tip, and the nostrils then massaged gently from outside. Most patients can apply the cream themselves, but must be supervised by a nurse as part of a regular ward routine. The nurse applies the cream to patients who are unable to do so themselves, by means of glass rods or swab sticks.

This method has been used for three years in two 30-bed wards and for one year in another, without producing neomycin-resistant staphylococci.

2. Initially, all superficial open lesions are sprayed with a mixture of neomycin, bacitracin, and polymyxin (Polybactrin, Calmic Ltd.) at every dressing. The inner layer of gauze is also sprayed. A controlled trial, to be reported separately, showed that this treatment protected a significant proportion of the lesions from staphylococcal colonization. Because it is expensive, the use of Polybactrin is stopped after some weeks, provided that routine swabs from patients' noses and open wounds show a marked reduction in staphylococcal cross-infection. Thereafter the lesions are treated instead with a sterile powder of calcium phosphate containing chlorhexidine dichloride $1 \%(w / w)$. The value of this measure is so far unproven. As an additional safeguard the dressings may be impregnated with chlorhexidine before autoclaving (V. G. Alder, personal communication).

3. Urine of urological patients is disinfected before emptying the urine bottles (see above). Special care is also taken to dispose safely of sputum and faeces which are heavily infected with staphylococci.

AGAINST VECTORS 1. Bedclothes, including blankets, bedcovers, and dressing gowns, are disinfected at intervals of not more than $\mathbf{1 4}$ days, or whenever the patient leaves hospital. High-temperature laundering is sufficient to disinfect cotton blankets and other non-woollen goods. Woollen blankets also may be disinfected in hot water, if rendered slightly acid (British Launderers' Research Association and the International Wool Secretariat, 1959), or by means of steam at subatmospheric pressure (V. G. Alder and W. A. Gillespie, to be published). If chemical methods are preferred, the choice lies between using a quaternary ammonium disinfectant during laundering, preferably by a one-stage method (e.g., Hytox process), and a gaseous disinfectant. Warm, moist formaldehyde vapour is reasonably effective if penetration is assisted by a partial vacuum (Gillespie and Alder, 1957). Best results are obtained by using an efficient pump to provide a high vacuum. Ethylene oxide has also been used to disinfect blankets (Freeman and Barwell, 1960).

2. Crockery is disinfected by heat or by means of a detergent mixture containing a quaternary ammonium compound (e.g., Vantropol, B.Q.).

3. The ward barber's brushes and razors are disinfected in $70 \%$ spirit for 10 minutes after use. A special trolley with a jar of spirit and sufficient brushes must be provided.

4. Nurses and other staff wash their hands with hexachlorophene toilet soap, dry with paper towels, and rub in Hibitane hand cream (chlorhexidine $1 \%$.

5. Patients' baths are disinfected by adding hexachlorophene to the actual bath water (Ayliffe, Alder, 0 and Gillespie, 1959). The water used for 'blanket $\varnothing$ bathing' bed-ridden patients is similarly treated. This $\stackrel{\mathcal{C}}{-}$ measure, and the next, also have a disinfectant action 0 on the skin.

6. The buttocks, back, and perineum of bed- $\stackrel{\mathbb{Q}}{\mathcal{Q}}$ ridden patients are dusted with hexachlorophene $\stackrel{\unrhd}{\varrho}$ talcum powder (Ster-Zac). 
STAPHYLOCOCCAL INFECTION IN OPERATING THEATRES

The control of staphylococcal cross-infection in the wards may reduce its incidence in the theatre, since some strains responsible for theatre infections originate in the wards (Gillespie et al., 1959). The treatment of pre-operative bath water, and the provision of freshly disinfected bedding are perhaps of special value.

In the theatre itself, disinfectants have important uses in the treatment of the patient's skin before incision, and the surgeon's hands before he puts on his gloves. These applications are dealt with by Dr. Lowbury (see page 85 ).

\section{FURUNCULOSIS IN NURSES}

Recurrent furunculosis is usually the result of reinfection from a carrier site on the patient's body. Many nurses become carriers of 'hospital' staphylococci, and the furunculosis which in some hospitals causes a good deal of minor ill-health, is often a consequence of cross-infection.

Gould and Cruikshank (1957) prevented recurrences of furunculosis by treating nasal carriage with antiseptic creams. Tulloch, Alder, and Gillespie (1960) found that in a minority of patients the reinfecting staphylococci came from non-nasal sites such as the perineum (especially when boils affected the lower part of the body) and from superficial lesions which, although often apparently trivial, might be colonized by staphylococci, e.g., external otitis, blepharitis, and eczematous areas. For maximum success in preventing recurrence they therefore recommend that treatment of nasal carriage with mixtures of neomycin and bacitracin (Neobacrin) or neomycin and chlorhexidine (Naseptin) in watermiscible creams should be supplemented by daily hexachlorophane baths and powder. Colonized areas of eczema, etc., were treated with creams or drops containing neomycin.

\section{REFERENCES}

Ayliffe, G. A. J., Alder, V. G., and Gillespie, W. A. (1959). Lancet, 2, 456.
Baldwin, J. N., Rheins, M. S., Sylvester, R. F., and Shaffer, T. E. (1957). Amer. J. Dis. Child., 94, 107.

British Launderers' Research Association and the International Wool Secretariat (1959). Joint Report: High Temperature Laundering of Woollen Hospital Blankets. Brit. Launderers Research Assn., London.

Colebrook, L. (1950). A New Approach to the Treatment of Burns and Scalds. Fine Technical Publications, London.

- (1954). 'Puerperal Infection (1800-1950).' In Kerr, J. M. Munro, Johnstone, R. W., and Phillips, M. H. Historical Review of British Obstetrics and Gynaecology, 1800-1950 p. 202. E. \& S. Livingstone, Edinburgh.

- Gibson, T., Todd, J. P., Clark, A. M., Brown, A., and Anderson, A. B. (1944). Spec. Rep. Ser. med. Res. Coun. (Lond.), No. 249.

$\longrightarrow$, and Maxted, W. R. (1933). J. Obstet. Gynaec. Brit. Emp., 40, 966.

Corner, Beryl D., Crowther, S. T., and Eades, Sheila M. (1960). Brit. med. J., 1, 1927.

Cunliffe, A. C. (1949). Lancet, 2, 411.

Donnison, Barbara, Gillespie, W. A., Simpson, K.. and Tozer, Rosemary C. (1960). Lancet, 1, 552.

Dukes, C. (1928). Proc. roy. Soc. Med., 22, 259.

Durham, M. P., Shooter, R. A., and Curwen, M. P. (1954). Brit. med. J., $2,1008$.

Farquharson, C. D., Penny, S. F., Edwards, H. E., and Barr, E. (1952). Canad. med. Ass. J., 67, 247.

Francis, A. E. (1959). Proc. roy. Soc. Med., 52, 998.

Freeman, M. A. R., and Barwell, C. F. (1960). J. Hyg. (Lond.), 58, 337.

Frisby, B. R. (1959). Lancet, 2, 57.

Gibbon, N. (1958). Brit. J. Urol., 30, 1.

Gillespie, W. A. (1956). Proc. roy. Soc. Med., 49, 1045.

$\longrightarrow$, and Alder, V. G. (1957). Lancet, 1, 632.

, Ayliffe, G. A. J., Bradbeer, J. W., and Wypkema, W. (1959). Ibid., 2, 781.

-, Linton, K. B., Miller, A., and Slade, N. (1960). J. clin. Path., $13,187$.

- Simpson, K., and Tozer, Rosemary C. (1958). Lancet, 2, 1075.

Gould, J. C., and Cruikshank, J. D. (1957). Ibid., 2, 1157.

Hudson, P. B., Sanger, G., and Sproul, Edith E. (1959). J. Amer. med. Ass., 169, 1549.

Hurst, Valerie. (1960). Pediatrics, 25, 204.

Jackson, D. M., Lowbury, E. J. L., and Topley, Elizabeth. (1951). Lancet, $2,137$.

Kass, E. H. (1957). Arch. intern. Med., 100, 709.

$\longrightarrow$, and Sossen, H. S. (1959). J. Amer. med. Ass.. 169. 1181.

Lowbury, E. J. L. (1957). Lancet, 2, 305.

-, (1960). Brit. med. J., 1, 994.

, and Cason, J. S. (1954). Ibid., 2, 914.

McLeod, J. W. (1958). Lancet, 1, 394.

Miller, A., Gillespie, W. A., Linton, K. B., Slade, N., and Mitchell, J. P. (1958). Ibid., 2, 608.

-, Linton, K. B., Gillespie, W. A., Slade, N., and Mitchell, J. P. (1960). Ibid., 1, 310.

Paterson, M. L., Barr, W., and Macdonald, S. (1960). J. Obstet. Gynaec. Brit. Emp., 67, 394.

Simpson, K., Tozer, Rosemary C., and Gillespie, W. A. (1960). Brit. med. J., 1,315 .

Sykes, G. (1958). Disinfection and Sterilization. E. \& F. N. Spon, London.

Tulloch, L. G., Alder, V. G., and Gillespie, W. A. (1960). Brit. med. J., 2,354 .

Williams, R. E. O., Blowers, R., Garrod, L. P., and Shooter, R. A. (1960). Hospital Infection-Causes and Prevention. Lloyd-Luke London. 